\title{
Erratum to: Equipment Selection for Mining: With Case Studies
}

\author{
Christina N. Burt and Louis Caccetta
}

\section{Erratum to:}

C. N. Burt and L. Caccetta, Equipment Selection for Mining: With Case Studies, Studies in Systems, Decision and Control 150, https://doi.org/10.1007/978-3-319-76255-5

In the original version of the book, the originator type "Authored Work" has to be now changed to "Edited Work" and the chapter author names have to be displayed in their respective chapters. The erratum book has been updated with the changes. 